\title{
Occupational Safety and Health in Nepal Revisited
}

\author{
Sunil Kumar Joshi
}

${ }^{1}$ Chief Editor, International Journal of Occupational Safety and Health (IJOSH)

Tosong he author had an opportunity to write an editorial on "Occupational Safety and Health in Nepal" for the inaugural issue of the International Journal of Occupational Safety and Health (IJOSH) in 2011. Occupational safety and health-related provisions were discussed in the milieu of the current Labour Act $1992^{1}$ and Labour Rules 1993². Labor Act 1992 had highlighted few issues and provisions on working hours, physical infrastructural setup, yearly medical examination and provisions of safety measures in work etc. Similarly, the Labour Rules 1993 discussed on the execution of the Labor Act 1992 and mostly emphasized on the workers' welfare-related issues, treatment, and compensation for occupational accidents. In this light, except for few enactments under the Labor Act 1992, the issues of occupational safety and health (OSH) were lacking legal backup.

The Labor Act, 2017 was passed by the Parliament on August 11, 2017. ${ }^{3}$ The New Labor Act has brought a complete change in the employment regime in Nepal. The New Labor Act has removed the headcount requirement for its applicability, as it is applicable to all workplaces regardless of a number of employees. Previous Act was applicable only to the workplaces where ten (10) or more people were employed. There were no provisions for medical insurance and accident insurance in the previous act. The new Labour Act specifies that there should be coverage of at least one hundred thousand rupees per year for every worker as part of the medical treatment cost. Similarly, there should be coverage of at least seven hundred thousand rupees for every worker as workplace injuries related

DOI: https://doi.org/10.3126/ijosh.v8i1.22921

\section{Corresponding Author}

Prof. Dr. Sunil Kumar Joshi

Chief Editor,

International Journal of Occupational Safety and Health (IJOSH)

E-mail: ijoshnepal@gmail.com

(c) 2018 IJOSH All rights reserved treatment cost. The premium for medical insurance is paid half by the employer and half by the employee, but the premium for the accident insurance is fully borne by the employer.

Other OHS related provisions included in the new Labour Act are:

- Preparation of Safety and Health Policy applicable to each workplace and such policy should be registered with the Labor Office.

- Formation of Safety and Health Committee where 20 or more workers are engaged in any workplace. There is provision for the formation of different $\mathrm{OHS}$ related committees as well.

- Employer's duties towards the workers which include making appropriate safety and health arrangement, arrangements ensuring no adverse effect on workers from use, operation, storage or transportation of chemical, physical or biological materials, disseminating necessary notice, information, and training related to safety and health, etc.

- Employee's duties related to safety and health at the workplace which include abstaining from doing any activities that are likely to affect the safety and health of any individual in the workplace, cooperate with the employer for proper implementation of the health and safety arrangements, to use the personal safety devices provided by the employer, etc.

- Authority delegated to the workers on stopping work anytime, in case of the immediate threat of any injury or adverse health effect or damage to the equipment in the workplace.

- Prevention of Communicable Diseases by barring the workers from joining their regular duty until the treatment is completed.

- All the expenses for the investigation and treatment of any work-related diseases should be provided by the employer. And where such disease cannot be cured the worker should be provided with compensation as prescribed. 
- Pregnant women should not be exposed to a hazardous work environment.

As the Labour Rules is mandatory to implement the New Labour Act, a meeting of the Council of Ministers held on 27 May 2018 has adopted the Labour Rules 2018. ${ }^{4}$ Labour Rules 2018 has further cleared the provisions of Labour Act 2017.

Major OSH related issues elaborated in the Labour Rules 2018 were detail process about the formulation of health and safety policy, formation of safety and health committee, additional duty of the employer on workplace safety and health, duties of manufacturers, importers and suppliers, specific provisions relating to the safety of the work processes having health hazards, and special provision relating to the employees performing intellectual work.

Additional provisions in the new Labour Rules were on notification of the workplace accidents and the list of occupational diseases, their treatment, and compensation if the disease cannot be cured. The new Labor Rules authorizes the Government of Nepal to publish a list of the occupational diseases in Nepal Gazette. It instructs on settlement of any dispute relating to whether or not an occupational disease by forming a committee comprising of specialized medical practitioners and other experts. The Labour Rules provide authority to the Ministry of Labour, Employment and Social Security to specify the medical costs and compensation to be paid to the workers with occupational diseases based on the recommendation provided by the committee.

Mandatory Labour audit is an important provision added in the new Labour Rules. It prescribes that the employer is required to conduct a labor audit as per the criteria defined by the Ministry of Labour, Employment and Social Security, every year by the end of the Nepali month of Poush, i.e. mid-January as per English calendar.

The process of forming different committees to decide whether the disease is of occupational origin or not, the degree of disability due to the occupational diseases, compensation to be paid to the workers are described in detail in the Social Security Scheme Procedural Guidelines $2018^{+}$to be approved by the Ministry of Labour, Employment and Social Security, Nepal soon. The Procedural Guidelines also contains the detail list of occupational diseases recognized by the Government of Nepal.

Though there are provisions of occupational safety and health in the new Labour Act, Labour Rules and the Social Security Scheme Procedural Guidelines, the legislation are silent on the supervision and monitoring of the implementation status of those legal binding documents. A separate occupational safety and health policy is still lacking. Nepal has yet to ratify various international declarations and protocols under $\mathrm{OSH}$ mainly ILO convention 155.

It is important to develop the concept of occupational safety and health as an integral part of the human value, rather than considering it as a legally binding concern. The State Government has to build the capacity of different provincial governments, employers, and workers on $\mathrm{OSH}$ needs and practices. The central government should prioritize the formation of apex government body specifically for $\mathrm{OSH}$. The regular process of dialogue, interactions and brainstorming sessions for new policy formulation and necessary amendments should continue and it should be associated with various training, capacity building, and skill transfer activities. It is equally important to promote $\mathrm{OSH}$ related scientific studies and publications in Nepal.

\section{References}

1. Government of Nepal. Ministry of Labour and Employment. Department of Labour. Labour act 2048. Cited on June 15, 2018. Available from : http://dol.gov. np/ckeditor/kcfinder/upload/files/OLabor Act\%2C 2048nep.pdf

2. Government of Nepal. Ministry of Labour and Employment. Department of Labour. Labour rules 2050. Cited on June 15, 2018. Available from : http://dol.gov. $\mathrm{np} /$ ckeditor/kcfinder/upload/files/SramNiyamawaliNEP 50.pdf

3. Government of Nepal. Ministry of Labour and Employment. Department of Labour. Labour act 2074. Cited on June 15, 2018. Available form: http://dol.gov. $\mathrm{np} / \mathrm{site} / \mathrm{cms} / 15$

4. Government of Nepal. Ministry of Labour and Employment. Department of Labour. Labour rules 2075. Cited on June 15, 2018. Available form: http://dol.gov. $\mathrm{np} / \mathrm{site} / \mathrm{cms} / 15$

The author was a team member of the committee that drafted the Social Security Scheme Procedural Guidelines 2018 